\title{
Main trends of biodiversity dynamics after natural and anthropogenic "catastrophes" in spruce forests of the European part of Russia
}

\author{
Nina Ulanova*, and Andrei Kaplevsky \\ Lomonosov Moscow State University, Biological Dep., 119234 Moscow, Russia
}

\begin{abstract}
We analyzed the main trends of the change in the species richness of phytocenoses after catastrophic natural (beetle outbreaks, windfalls) and anthropogenic (clear cutting) disturbances. We examined the dynamics of the structural diversity of species richness of herb-dwarf scrubs layer with different reforestation technologies after the death of spruce stands. The study of similarity and ordination of vegetation showed the proximity of the undamaged forest to the unharvested stand, and the difference of these phytocenoses from clear-cut. The main determining factor of species richness was the intensity of phytocenosis disturbance after catastrophes. The reforestation dynamics of phytocenoses after catastrophic disturbances were analyzed. Clear cutting led to the formation of meadow communities with a sharp increase in the species and structural diversity of phytocenoses.
\end{abstract}

\section{Introduction}

The problem of conservation of forest biodiversity is one of the most important challenges in biology and ecology in 20-21 centuries and the central task of wildlife conservation. All anthropogenic (clear cutting, large area forest fires, industrial pollution) and natural (massive insect infestations, catastrophic windfalls) disturbances are considered to be negative factors leading to a reduction in biodiversity [1]. The large-scale death of forests leads to the reduction of diversity of biotopes, phytochors, and phytocenoses, the extinction of species and the reduction of their intraspecific genetic diversity. These conventional ideas are based on the comparison of data from different researchers, construction of spatiotemporal patterns, etc. However, identification of change patterns in species composition of communities can only be done by monitoring of the biodiversity of permanent sample plots in a series of phytocenoses along a relief gradient within a limited area (phytocatenae) for a long period of time after catastrophic disturbances [2].

We focus on an understudied aspect that is the dynamics of plant species composition (alpha-diversity) in the spruce forests of southern taiga and mixed coniferous-deciduous forests of the European part of Russia after "catastrophic" disturbances.

The natural environmental mechanism of the decay of spruce forest stand (which is the final stage of the dynamics of spruce phytocenoses at the final stage of succession in the

\footnotetext{
*Corresponding author: NUlanova@mail.ru
} 
European part of Russia) is implemented in catastrophic windfalls, fires or dead-wood patches during outbreaks of eight-dentated bark beetle (Ips typographus L.).

\section{The intensity of disturbances in phytocenoses after natural and anthropogenic disasters}

Catastrophic natural phenomena that cause the death of spruce forests create disturbances that vary in scale (Fig. 1). During fires, a significant part of tree stands and under-growing vegetation dies, and there is a very wide range of soil damage. In the case of catastrophic windfalls, the scale of the loss of the stand and the ground cover varies, and the soil cover damage is minor [3]. With partial preservation of the forest stand and undergrowth in windfalls, only a redistribution of dominant species with a slight change in the species composition occurs in the herb-dwarf shrubs layer [2, 4]. In areas of spruce drying during outbreaks of the eight-dentated bark beetle, the soil and ground cover remains mostly untouched, but the proportion of dead spruce varies from 0 to $100 \%$. The degree of ecosystem disturbance during disasters that lead to the destruction of spruce forests determines the rate of vegetation restoration in areas of fire-damaged forest, windfalls, and in the epicenters of spruce drying.

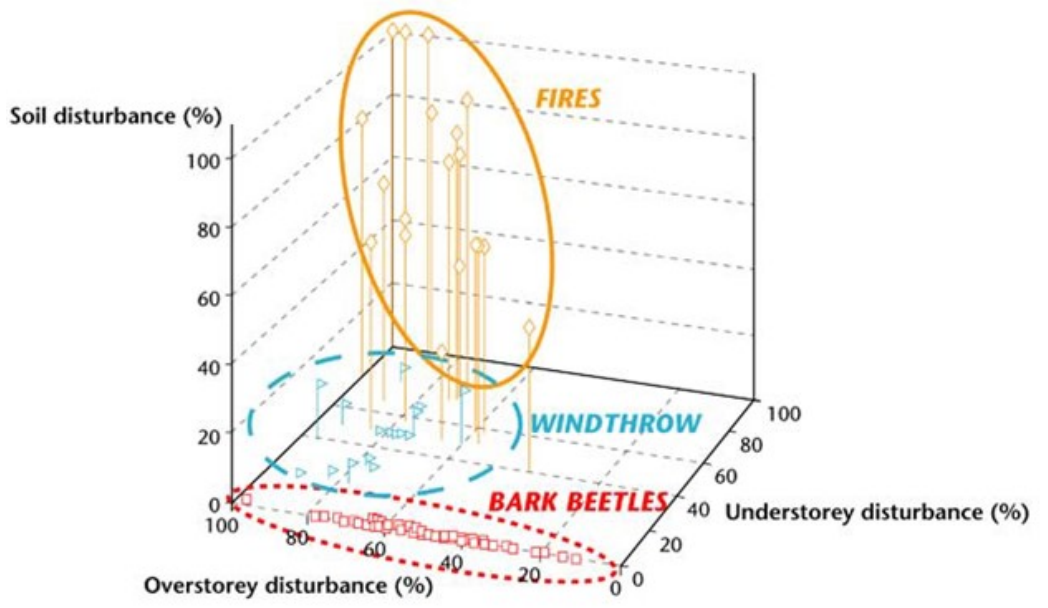

Fig. 1. The intensity of the destruction of the forest stand, ground cover and soil in phytocenoses after natural catastrophes (fire, massive windfall, outbreaks of bark beetle) [5].

\section{Increase of biodiversity: species richness and structural diversity}

Natural and anthropogenic disasters lead to transformations of the original phytocenoses of different intensity. As a result, an increase in biodiversity in new communities occurs; in areas of dead-wood spruce it is insignificant, and it is higher in areas of catastrophic windfalls. With the complete destruction of spruce forest stand (not only the dead trees) in the course of clear cutting, a radical change in the soil cover [6] and transformation of forest communities into grass and shrub communities occurs, which leads to a fundamental change in the vegetation cover. In newly formed meadow communities, biodiversity increases dramatically due to emergence of non-forest species [2]. Additionally, a metaanalysis of the results of 238 studies of biodiversity in various forests of the world revealed an increase in the species richness of vascular plants after catastrophic windfalls and death 
of the forest stand as a result of outbreaks of bark beetles and logging [7].

Let us consider changes in vegetation in areas of spruce drying in 2012 in the western part of the Moscow Region (Zvenigorod Biological Station of Moscow State University) as an example.

In 2013, we established three permanent sample plots of the same size $\left(800 \mathrm{~m}^{2}\right)$ in a spruce-weaselsnout forest: one in an area with the spruce forest stand that died in 2012 (bark beetle infection), one in an area of clear cutting of dead-wood in the winter of 201213 , and one in an area with living spruce tree stand (control). Studies were conducted in August 2014, 2015 and 2016 using a uniform methodology. Three transects $40 \mathrm{~m}$ long and $40 \mathrm{~cm}$ wide each were made on the sample plots. The frequency of species in the herbdwarf-shrubs layer was studied at each meter of the transect, using a rigid frame $40 \times 100$ $\mathrm{cm}$ in size, divided into $20 \times 20 \mathrm{~cm}$ squares by removable threads.

In spruce dead-wood forest, species retained their dominance in the herb-dwarf shrubs layer (Fig. 2). After snagging, the floristic composition of the herb-dwarf-shrub layer increased by a factor of 2, compared to the undisturbed spruce stand, as a result of the death of the herb-dwarf-shrub layer, disturbances of moss and soil cover during the wood transportation, burning of cuttings and subsequent introduction of new species. Other species became dominant. As a result of significant soil disturbances, patchiness of the herb-dwarf-shrub layer became very high.

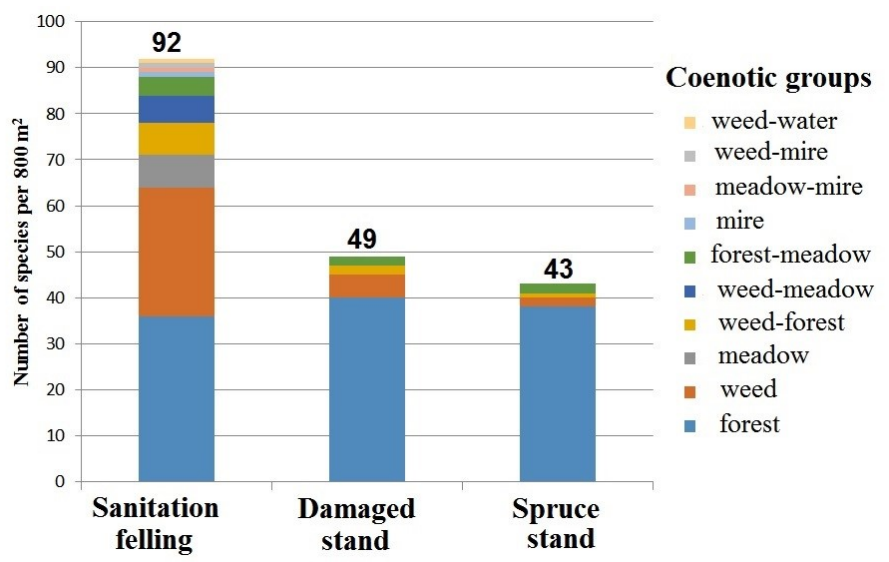

Fig. 2. The coenotic structure of the species richness of the herb-dwarf-scrub layer in the spruceweaselsnout stand (control), in the second year after the death of the forest stand with the sanitation felling of dead-wood and with the preservation of the dead-wood (damaged stand).

The coenotic spectrum of the herb-dwarf-shrub layer in the spruce forest after the death of spruce trees corresponds to the spectrum of the original forest (Fig. 2). During the second year, there was a change in the frequency of species in the herb-dwarf-shrub layer and species of new coenotic groups characteristic of the original forest were introduced. The frequency of moss cover species decreased due to shading from growing hazel shrubs. In the slash area, the increase in the number of coenotic groups was doubled due to the introduction of herbaceous species and mosses that were not characteristic for the original community. In the slash area, the proportion of forest species significantly decreased, and the proportion of weed, meadow and weed-meadow species increased. The type of the phytocenosis of the slash areas can be characterized as forest-meadow.

\section{Regenerative dynamics of phytocenoses after catastrophic disturbances}


Significant disturbances of phytocenoses and soils lead to the following types of successions: demutations, secondary incomplete and quasi-primary. Changes in vegetation depend on the initial forest type. Thus, in the areas of drying of spruce trees in the Moscow Region, in spruce-blueberry and spruce-blueberry-shamrock forests, fluctuations go through a stage with rowanberry forest with spruce undergrowth. In the spruce-weaselsnout and complex spruce forests, demutation goes through a stage of lime and maple forests with spruce undergrowth. In complex spruce forests with hazel, the incomplete secondary succession ends with a hazel shrub forest.

An alternative method of forest management (preservation of the dead stand and natural regeneration of the forest) is possible only in forests that have a protected status. The preservation of dry stands and wind-fall areas in spruce forests leads to the natural course of reforestation, which preserves the forest phytocenoses and changes only the proportions of dominant species in the forest stand. As a result, mixed stands with broad-leaved species form, which are highly resistant to pests and forest diseases. Forests with a complex structure replace monocultures of spruce, which contributes to the restoration of the diversity of forests characteristic of the coniferous-deciduous forest zone. Such natural forests are most likely characteristic of the coniferous-deciduous forest zone.

Forest management in spruce forests requires clear sanitation felling of the dead tree stand in the event of bark beetle outbreaks, as well as the clearing of catastrophic windfall and fire sites. The massive use of clear cuttings over the last ten years has led to an increase in the slash area where meadow communities have formed. In new meadow communities the biodiversity increases dramatically due to the presence of non-forest species [2]. From the point of view of a biologist, this process cannot be considered negative for nature. If our ideology requires an increase in biodiversity, then the formation of meadow vegetation is the best solution. Several publications that came out in recent years raise the question of the importance of the first succession stages for increase of forest biodiversity $[7,8,9,10]$.

\section{References}

1. A.S. Isaev, Monitoring of biological diversity of Russian forests: methodology and methods (M, Science, 2008).

2. N.G. Ulanova, Herald of TVGU. Series: Biology and Ecology, 3 (2018)

3. N.G. Ulanova, For. Ecol. Manag., 135 (2000).

4. N.G. Ulanova, O.V. Cherednichenko, Izvestia of Samara Sc.C. RAS, 14 (2012)

5. P.J. Burton, BC J. Ecos. and Manag., 9 (2008)

6. A.A. Dymov, Eurasian Soil Science, 7 (2017)

7. S. Thorn, C. Bässler, R. Brandl, P.J. Burton, R. Cahall, J.L. Campbell, J. Castro, C.Y. Choi, T. Cobb, D.C. Donato, E. Durska, J.B. Fontaine, S. Gauthier, C. Hebert, T. Hothorn, R.L. Hutto, E.J. Lee, A.B. Leverkus, D.B. Lindenmayer, M.K. Obrist et al., J. Appl. Ecol., 55 (2018).

8. M.E. Swanson, J.F. Franklin, Ch.M. Crisafulli, D.A. Della Sala, R.L. Hutto, D.B. Lindenmayer, Fr.J. Swanson, Front. Ecol. Environ., 9 (2011).

9. D.P. Blair, L.M. McBurney, W. Blanchard, S.C. Bank, D.B. Lindenmaye, Ecological Appl., 26 (2016).

10. P.J. Fornwalt, Ch.C. Rhoades, R.M. Hubbard, R.L. Harris, A.M. Faist, W.D. Bowman, For. Ecol. Manag., 409 (2018) 